\section{Ranibizumab: a medical treatment that requires surgical administration}

Eye (2011) 25, 399-401; doi:10.1038/eye.2011.3

Age-related macular degeneration (AMD) is a chronic condition that is one of the leading causes of irreversible blindness in people over 50 years of age. AMD is the most common cause of vision loss in the western world, and globally is the third most common cause after cataracts and glaucoma. In 2002, the World Health Organization reported that AMD accounted for $8.7 \%$ of the 37 million cases of blindness worldwide-over 3.2 million cases. ${ }^{1}$

AMD is classified into two forms: non-exudative ('dry') AMD and exudative ('wet') AMD. With dry AMD, cellular debris accumulates between the retina and the choroid, which contains the blood vessels that supply nourishment to the retina, particularly the macula (central retina). This results in atrophy of the retina and the underlying pigment epithelial layer, causing slow and progressive loss of vision. Wet AMD is far more severe and may develop de novo or from pre-existing dry AMD. In wet AMD, new blood vessels also begin to grow from the choroid (choroidal neovascularization; CNV). Bleeding, leaking, and scarring caused by these blood vessels distorts and blurs the central vision: with time, the bleeding, fluid leakage, and subsequent scar formation damages the retina, and can eventually lead to severe vision loss or blindness. Although wet AMD is the less common form, occurring in 10-15\% of cases, it accounts for $\sim 80-90 \%$ of AMD-associated severe visual loss. ${ }^{2}$ Before the development of the first treatment for wet AMD, predominantly classic CNV usually led to permanent and almost complete central vision loss within 3-6 months of diagnosis. ${ }^{3}$

The first approved pharmacological treatment of wet AMD was verteporfin (Visudyne,
WM Amoaku

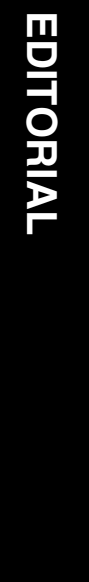

Novartis Pharma AG, Basel, Switzerland) in 2001, a light-activated drug for use in photodynamic therapy (PDT). ${ }^{4}$ In 2004 and 2006, respectively, the vascular endothelial growth factor (VEGF) inhibitors pegaptanib (Macugen, Gilead Sciences, Foster City, CA, USA and Pfizer Inc., New York City, NY, USA) and ranibizumab (Lucentis, Genentech Inc., San Francisco, CA, USA and Novartis) were licensed by the US Food and Drug Administration (FDA) for the treatment of wet AMD. ${ }^{5,6}$ On the basis of the results of several clinical trials (Table 1), ranibizumab is currently considered the gold-standard of care for wet AMD as reported by the UK Royal College of Ophthalmologists, ${ }^{7}$ and has been endorsed by other professional societies and associations (eg, the Swiss VitreoRetinal Group ${ }^{8}$ ) as well as the UK National Institute for Health and Clinical Excellence (NICE). ${ }^{9}$

Ranibizumab is a therapeutic antibody fragment that binds to human VEGF-A isoforms and prevents receptor binding. VEGF is a regulator of normal and abnormal angiogenesis, and intraocular VEGF levels correlate with blood vessel formation or increased vascular permeability in a number of retinal disorders, including wet AMD. ${ }^{10}$ By blocking the action of VEGF, ranibizumab can prevent and reverse vision loss caused by wet AMD-associated CNV. ${ }^{11}$ Ranibizumab was specifically developed for application in ophthalmology from murine anti-VEGF antibody A.4.6.1. ${ }^{12}$ and is specifically manufactured according to US Pharmacopeia specifications for injections into the eye. ${ }^{13,14}$ This ensures it has fewer particulates compared with products developed for intravenous use, and thus a putatively lower potential for ocular irritation and inflammation. ${ }^{15}$

Ranibizumab is manufactured as a $10 \mathrm{mg} / \mathrm{ml}$ solution in single-use vials containing $0.2 \mathrm{ml}$ of ranibizumab. ${ }^{6}$ To be effective, $0.05 \mathrm{ml}$ of the
Queen's Medical Centre, University Hospital, Nottingham, UK

Correspondence: WM Amoaku, B Floor, Eye and ENT Centre, University Hospital, Queen's Medical Centre,

Nottingham, NG7 2UH, UK Tel: + 44 (0)115 95 15151; Fax: + 44 (0)115962 7765 . E-mail:wma@nottingham. ac.uk 
Table 1 Common clinical issues and concerns

Issue Response

Why is a surgical procedure required?

Who can administer treatment?

How much does each treatment cost and for how long would a treatment regimen typically last?

What other pharmacological treatment options are available for wet AMD?

Why should unlicensed intravitreal use of bevacizumab be avoided, if possible?
To exert a full therapeutic effect on the new blood vessels that form in wet AMD-related CNV, ranibizumab must be administered locally. Therefore, the easiest mode of administration is through intravitreal injection, which is considered a surgical procedure.

The treatment cannot be self-administered. It is a delicate procedure that needs to be carried out in a very specific manner, using specialized equipment in a sterile environment, which includes detailed preparation and follow-up to reduce the likelihood of serious complications. As such, the procedure should only be carried out by a qualified ophthalmologist with experience of performing intravitreal injections.

Costs will vary, but NICE reports that a single ranibizumab injection in the UK costs $£ 761.20$, with a 2-year treatment cost of around $£ 10700$, assuming a typical course (14 injections). When the response rate of treatment is considered $(\geq 70 \%)$, ranibizumab has been shown to be a cost-effective therapy. ${ }^{20}$

Aside from ranibizumab, pegaptanib (Macugen) and verteporfin (Visudyne) PDT are currently the only other approved pharmacological treatments for wet AMD. Ranibizumab has shown superior efficacy over both of these treatments. ${ }^{21-24}$ The anti-VEGF agent bevacizumab has not been approved or systematically evaluated for intravitreal use.

Bevacizumab is not consistent with regulatory standards for intravitreal use. ${ }^{25}$ As an intravenous drug, it is not prepared to the rigorous ophthalmic standards of ranibizumab or pegaptanib, and may put the patient at higher risk of adverse events. ${ }^{26,27}$ Bevacizumab is not recommended when approved products for wet AMD are available. solution ( $0.5 \mathrm{mg}$ ranibizumab) must be injected directly into the vitreous humour of the eye. This is an invasive and specialized procedure, which differs from typical cutaneous and intramuscular injections in several important ways. First, the eye is an immunopriviledged, delicate, and important sensory organ and as such the procedure requires a very high level of sterility and precision. ${ }^{6}$ Second, unlike some injections such as insulin administration in diabetic patients, ranibizumab injections cannot be self-administered. Because of the delicate location of the injection, and the expertise required to avoid or address any severe complications that may occur (including retinal detachment, traumatic cataracts, and endophthalmitis), they must be performed by a qualified ophthalmologist experienced in intravitreal injections. ${ }^{16}$ Third, full aseptic technique should be adhered to at all times, including the use of a clean room or operating theatre and surgically sterile equipment. $6,16,17$ Lastly, appropriate anaesthesia and broad-spectrum microbicides are required before the procedure, and afterwards essential monitoring for infection, inflammation, and other complications requires specialized medical equipment, such as a tonometer or biomicroscope. ${ }^{6}$ For these reasons, the intravitreal injection of ranibizumab, or indeed any intravitreal injection, is considered a surgical procedure.

As such, although ranibizumab is a drug, it can only be administered by intravitreal injection for the treatment of wet AMD-associated CNV. It should therefore be considered both a surgical and medical treatment, and should be subject to healthcare regulations and reimbursement appropriate to both classifications. Additional issues are addressed in Table 1.

The author is Vice President of the Royal College of Ophthalmologists (London) and Chairman of its Scientific Committee (whose duties include assessing the impact of new intravitreal injections and other AMD treatments in the British National Health Service). He is also Associate Professor at the University of Nottingham and Honorary Consultant Ophthalmic Surgeon at Queen's Medical Centre University Hospital, Nottingham, UK. In his professional opinion, ranibizumab is a drug therapy. However, it needs to be administered through a surgical procedure undertaken by clinicians experienced in such procedures, that is, a trained ophthalmologist. This is because the procedure is potentially dangerous and can result in permanent loss of eyesight. ${ }^{18}$ One example is the sudden occlusion of optic nerve head perfusion, which if not treated within 3 min can result in permanent vision loss. ${ }^{18}$ Other serious risks include traumatic cataracts, retinal detachments, and acute endophthalmitis. ${ }^{19}$

In conclusion, ranibizumab is a pharmacological treatment that can only be delivered via a surgical procedure, which requires a trained specialist, cannot be self-administered, and should be performed in a clean room or operating theatre with sterile equipment. Ranibizumab should therefore be considered both a medical and surgical treatment, and should be subject to 
healthcare regulations and reimbursement appropriate to both classifications.

\section{Conflict of interest}

W Amoaku has received travel grants and speaker honoraria from Allergan, Novartis Pharma, and Pfizer, and served on Advisory Boards of Allergan, Novartis, and Pfizer. He has participated in research sponsored by Bausch and Lomb, Novartis, and Pfizer, for which his institution received funding from these organizations.

\section{References}

1 Resnikoff S, Pascolini D, Etya'ale D, Kocur I, Pararajasegaram R, Pokharel GP et al. Global data on visual impairment in the year 2002. Bull World Health Organ 2004; 82(11): 844-851.

2 Ferris III FL, Fine SL, Hyman L. Age-related macular degeneration and blindness due to neovascular maculopathy. Arch Ophthalmol 1984; 102(11): 1640-1642.

3 Bressler NM, Arnold J, Benchaboune M, Blumenkranz MS, Fish GE, Gragoudas ES et al. Verteporfin therapy of subfoveal choroidal neovascularization in patients with age-related macular degeneration: additional information regarding baseline lesion composition's impact on vision outcomes-TAP report No. 3. Arch Ophthalmol 2002; 120(11): 1443-1454.

4 Novartis. Verteporfin prescribing information. (accessed 17 May 2009 at http:/ /www.visudyne.com/assets/pdf/ PI.pdf). 2001.

5 Gilead. Macugen prescribing information. (accessed 18 May 2010 at http:/ /www.macugen.com/macugen USPI.pdf). 2004

6 Genentech. Lucentis prescribing information. (accessed 18 May 2010 at http://www.gene.com/gene/products/ information/pdf/lucentis-prescribing.pdf). 2006.

7 The Royal College of Ophthalmologists. The intravitreal use of bevacizumab (Avastin) in age-related macular degeneration. (accessed 22 October 2009 at http://www.rcophth.ac.uk/docs/publications/publishedguidelines/AVASTIN_-_The_Intravitreal_Use_of_ Bevacizumab_-_24th_February_2009.pdf).

8 Wolf S, Pournaras CJ, Garweg J, Gerding H, Guex-Crosier Y, Kopp B et al. Statement of the Swiss VitreoRetinal Group (SVRG) on current therapeutic options in neovascular age-related macular degeneration. (accessed 7 Jul 2010 at http://en.calameo.com/read/000110316f5e56d9c6bab). 2010.

9 NICE. Technology appraisal guidance 155: ranibizumab and pegaptanib for the treatment of age-related macular degeneration. (accessed 18 May 2010 from http:// guidance.nice.org.uk/TA155). 2008.

10 Ferrara N, Gerber HP. The role of vascular endothelial growth factor in angiogenesis. Acta Haematol 2001; 106(4): 148-156.

11 Rosenfeld PJ, Brown DM, Heier JS, Boyer DS, Kaiser PK, Chung CY et al. Ranibizumab for neovascular age-related macular degeneration. $N$ Engl J Med 2006; 355(14): 1419-1431.
12 Ferrara N, Damico L, Shams N, Lowman H, Kim R. Development of ranibizumab, an anti-vascular endothelial growth factor antigen binding fragment, as therapy for neovascular age-related macular degeneration. Retina 2006; 26(8): 859-870.

13 Muller YA, Chen Y, Christinger HW, Li B, Cunningham BC, Lowman HB et al. VEGF and the Fab fragment of a humanized neutralizing antibody: crystal structure of the complex at $2.4 \AA$ resolution and mutational analysis of the interface. Structure 1998; 6(9): 1153-1167.

14 Lowe J, Araujo J, Yang J, Reich M, Oldendorp A, Shiu V et al. Ranibizumab inhibits multiple forms of biologically active vascular endothelial growth factor in vitro and in vivo. Exp Eye Res 2007; 85(4): 425-430.

15 Berger AB, Sharma S. Severe intraocular inflammation/ endophthalmitis following off-label treatment with intravitreal bevacizumab. Ophthalmology Scientific Update, Faculty of Medicine, University of Toronto 2009: 1-8.

16 Amoaku W, Pearce I, Browning A. The Royal College of Ophthalmologists. Intravitreal Injections Procedure Guidelines. (accessed 14 June 2010 at http://www.rcophth. ac.uk/docs/scientific/IVTRevisionfinal2009.pdf).

17 NHS Estates. Infection Control in the Built Environment. The Stationery Office: London, 2002.

18 Aiello LP, Brucker AJ, Chang S, Chang S, Cunningham Jr ET, D'Amico DJ et al. Evolving guidelines for intravitreous injections. Retina 2004; 24(5 Suppl): S3-S19.

19 Schmidt-Erfurth U. Clinical safety of ranibizumab in age-related macular degeneration. Expert Opin Drug Saf 2010; 9(1): 149-165.

20 Cohen SY, Bremond-Gignac D, Quentel G, Mimoun G, Citterio T, Bisot-Locard $S$ et al. Cost-effectiveness sequential modeling of ranibizumab versus usual care in age-related macular degeneration. Graefes Arch Clin Exp Ophthalmol 2008; 246(11): 1527-1534.

21 Rosenfeld PJ, Rich RM, Lalwani GA. Ranibizumab: phase III clinical trial results. Ophthalmol Clin North Am 2006; 19(3): 361-372.

22 D'Amico DJ, Masonson HN, Patel M, Adamis AP, Cunningham Jr ET, Guyer DR et al. Pegaptanib sodium for neovascular age-related macular degeneration: two-year safety results of the two prospective, multicenter, controlled clinical trials. Ophthalmology 2006; 113(6): 992-1001.e6.

23 Brown DM, Kaiser PK, Michels M, Soubrane G, Heier JS, Kim RY et al. Ranibizumab versus verteporfin for neovascular age-related macular degeneration. $N$ Engl J Med 2006; 355(14): 1432-1444.

24 Brown DM, Michels M, Kaiser PK, Heier JS, Sy JP, Ianchulev $\mathrm{T}$. Ranibizumab versus verteporfin photodynamic therapy for neovascular age-related macular degeneration: two-year results of the ANCHOR study. Ophthalmology 2009; 116(1): 57-65.e5.

25 Killick J, Berghe P. Does promoting off-label use of medicines on budgetary grounds risk jeopardising the integrity of the marketing authorisation requirement system? Pharmaceutical Law Insight 2009; 6: 4-5.

26 Kahook MY, Kimura AE, Wong LJ, Ammar DA, Maycotte MA, Mandava N. Sustained elevation in intraocular pressure associated with intravitreal bevacizumab injections. Ophthalmic Surg Lasers Imaging 2009; 40(3): 293-295.

27 Kahook MY, Liu L, Ruzycki P, Mandava N, Carpenter JF, Petrash JM et al. High-molecular-weight aggregates in repackaged bevacizumab. Retina 2010; 30(6): 887-892. 